\title{
A Commentary on Opium Dependence and COVID-19 in the North of
}

\section{Iran}

\author{
Saeed Nateghi ${ }^{1}$ and Hosein Effatpanah ${ }^{2, *}$ \\ ${ }^{1}$ School of Medicine, Ziaeian Hospital, International Campus, Tehran University of Medical Sciences, Tehran, Iran \\ ${ }^{2}$ Department of Public Health, Asadabad School of Medical Sciences, Asadabad, Iran \\ "Corresponding author: Department of Public Health, Asadabad School of Medical Sciences, Asadabad, Iran. Tel: +98-9123787394, Email: m.effatpanah@gmail.com \\ Received 2020 May 30; Revised 2020 July 05; Accepted 2020 August 11.
}

Keywords: Addiction, Drug Abuse, Drug Dependence

\section{Dear Editor,}

Recently, an important research report has been published by Saeedi et al. (1) in the Iranian Journal of Psychiatry and Behavioral Sciences. The authors conducted a study of COVID-19 in 93 hospitalized patients. The study findings indicated that $10.8 \%$ of the infected patients were opiumdependent. Most importantly, the odds ratio related to death was found to be $3.59 \%$. Most participants were middle-aged (56.3-years-old) and male (54.8\%) (1). While no significant gender differences were reported, the high rate of mortality highlighted the crucial role of comorbidities in increasing fatality in infected patients. A substantial body of research acknowledges that illicit drug use, especially opium and methamphetamine, is a serious health problem in Iran $(2,3)$, and effective treatments need to be implemented for this vulnerable population on a large scale $(4,5)$. Methamphetamine use is associated with a wide range of harms, including high-risk behaviors, poor mental health, impaired physical health, and poor treatment outcomes, and compliance (4-7). However, the problem of COVID-19 highlights how this high-risk population may be vulnerable to death and serious physical and psychological impacts. Saeedi et al. (1) reported that poor personal hygiene and lack of social distancing were the main factors associated with the prevalence of COVID-19 among opium-dependent patients. The main lessons from this study are as follows.

First, it is necessary for service providers and health policymakers to consider a specific site for the medical treatment of such infected patients. All comorbidities such as poor nutrition, poor hygiene, and concurrent physical disorders, need to be managed at the same time to reduce the mortality rate in opium-dependent patients. However, a large proportion of opiate-dependent people in
Iran also uses methamphetamine (2-4), which may make them more vulnerable to the harms of COVID-19. Therefore, we still need to conduct more research on the mortality rate of polydrug users who are infected with COVID-19 in Iran.

Second, a large number of other vulnerable populations such as old people, regular smokers, pregnant and breastfeeding women, people with specific disorders such as diabetes, serious lung, heart, and kidney problems, and cancer may also need special attention for receiving comprehensive medical and treatment services at the time of coronavirus pandemic. Some of them may be dependent on opium and methamphetamine. The role of a series of comorbidities in increasing the mortality rate related to COVID-19 needs to be investigated.

The authors concluded that opium dependence makes people more susceptible to the harms associated with COVID-19 (1). Therefore, opium dependence can increase the rate of mortality in infected patients (1). Some studies highlight the role of health promotion in improving medical conditions (7-9). These issues need to be considered in treating COVID-19 in opium and methamphetaminedependent patients. To conclude, paying professional attention to this vulnerable population may reduce the total rate of mortality related to COVID-19 in the community.

\section{Footnotes}

Authors' Contribution: All authors have contributed to writing, editing, and revising this editorial.

Conflict of Interests: There is no conflict of interest. Funding/Support: There is no funding or support. 


\section{References}

1. Saeedi M, Omrani-Nava V, Maleki I, Hedayatizadeh-Omran A, Ahmadi A, Moosazadeh M, et al. Opium addiction and COVID-19: Truth or false beliefs. Iran J Psychiatry Behav Sci. 2020;14(2). doi:10.5812/ijpbs.103509.

2. Effatpanah M, Moradi A. Methamphetamine dependence and technology-based interventions in Iran. Iran J Psychiatry Behav Sci. 2018;12(2). doi: 10.5812/ijpbs.62935.

3. Rafiey H, Ghaderi S, Morovat B, Noori R, Effatpanah M, Mahjoub A, et al. Amphetamine type stimulants use in the adult population of Tehran: Implications for long term rehabilitation. Iran Rehabil J. 2017;15(4):303-8. doi:10.29252/nrip.irj.15.4.303.

4. Massah O, Effatpanah M, Shishehgar S. Matrix model for methamphetamine dependence among iranian female methadone patients: The first report from the most populated Persian Gulf Country. Iran Rehabil J. 2017;15(3):193-8. doi: 10.29252/nrip.irj.15.3.193.

5. Shakiba K, Effatpanah M, Moradi A. Cognitive-behavioral therapy for methamphetamine dependence among methadone-maintained pa- tients. Iran J Psychiatry Behav Sci. 2018;12(2). doi: 10.5812/ijpbs.63615.

6. Dana S, Effatpanah M, Mahjoub A. The new epidemic problem of psychoactive drugs at drug treatment centers of Iran: Implications for education, prevention and treatment. Iran J Psychiatry Behav Sci. 2018;12(2). doi: 10.5812/ijpbs.63555.

7. Tavakoli M, Effatpanah M, Moradi A, Mahjoub A. Methamphetamine dependence among iranian female methadone patients: A crosssectional survey of three cities of Iran. Iran J Psychiatry Behav Sci. 2018;12(2). doi: 10.5812/ijpbs.62866.

8. Khoramizadeh M, Effatpanah M, Mostaghimi A, Rezaei M, Mahjoub A, Shishehgar S. Treatment of amphetamine abuse/use disorder: A systematic review of a recent health concern. Daru. 2019;27(2):743-53. doi: 10.1007/s40199-019-00282-3. [PubMed: 31228128]. [PubMed Central: PMC6895313].

9. Salimi S, Effatpanah M, Mahjoub A. Motivational interviewing can facilitate entry to matrix treatment for methamphetamine dependence. Iran J Psychiatry Behav Sci. 2018;12(2). doi:10.5812/ijpbs.63560. 